Article

\title{
A Case Study of the Benefits of the Science Learning Partnerships in Early Years and Primary Education in England
}

\author{
Deborah Emily Outhwaite ${ }^{1, *}$, , Jane Banham ${ }^{2}$ and Anna Cummings ${ }^{3}$
}

1 Centre for Higher Education Studies, University of Liverpool, Liverpool L69 3BX, UK

2 Primary Science Facilitator, STEM Learning, York Y010 5DD, UK; jane.banham@btopenworld.com

3 Finance Department, Developing Teachers of Science Association, Derby DE65 9EL, UK; finance@dtsa.org.uk

* Correspondence: Deborah.Outhwaite@liverpool.ac.uk

check for

updates

Citation: Outhwaite, D.E.; Banham,

J.; Cummings, A. A Case Study of the Benefits of the Science Learning Partnerships in Early Years and Primary Education in England. Educ. Sci. 2022, 12, 107. https://doi.org/ 10.3390/educsci12020107

Academic Editors: Krishan Kumar Sood and Kelum A.A. Gamage

Received: 30 October 2021 Accepted: 31 January 2022 Published: 3 February 2022

Publisher's Note: MDPI stays neutral with regard to jurisdictional claims in published maps and institutional affiliations.

Copyright: (C) 2022 by the authors. Licensee MDPI, Basel, Switzerland. This article is an open access article distributed under the terms and conditions of the Creative Commons Attribution (CC BY) license (https:// creativecommons.org/licenses/by/ $4.0 /)$.

\begin{abstract}
This paper charts the recent history of the STEM Learning UK contracts with local Science Learning Partnerships (SLPs) and identifies what leadership has been made available to support the Early Years and Primary school sector. A case study approach is taken using 'Super SLP' hubs in England. Curriculum Hubs exist in core subject areas such as maths, English, science and computing. They have recently been expanded to include Behaviour Hubs. This forms the current DfE strategy of Teaching School Hubs (TSHs), i.e., to offer system support and a full career-length support for all stages of teacher-career and leadership development. This paper charts the changes to the Early Years (EY) and Primary teacher support networks, in science particularly, and examines what they provide and how this can be improved, and discusses, through session evaluation and feedback, what teachers have appreciated the most.
\end{abstract}

Keywords: creative leadership; educational leadership; early years science; primary science; science learning partnership; science education; STEM

\section{Introduction}

The development of careers and education in Science, Technology, Engineering and Maths (STEM) is a critical part of any economy. In England, the Department for Education (DfE) has helped to fund organisations such as STEM Learning UK [1], in order to help develop the education infrastructure around these scientific subject areas. This paper charts the recent history of the STEM Learning UK contracts with reference to their local Science Learning Partnerships (SLPs) and looks specifically at what leadership has been made available to support the Early Years and Primary school sector. The case study in this paper comes from a 'Super SLP' acting as one of the Department for Education's (DfE) Curriculum Hubs in the Midlands, England, UK. These curriculum hubs exist in a number of core subject areas such as maths, English, science and computing. The 'Golden Threads' of the system range from Initial Teacher Training and Education (ITTE), through the mentoring of teachers on the Early Career Framework (ECF), to this Continuing Professional Development (CPD) that these curriculum hubs provide, through to the National Professional Qualifications (NPQs) for all stages of teacher-career and leadership development.

This paper charts the changes to the Early Years (EY) and Primary teacher support networks in science and examines a case study from 2018-2020 of what has been provided across a particular area. How this CPD offer has been improved is examined through teacher and facilitator collaboration. The paper discusses the political backdrop that this project has operated under and demonstrates (through session evaluation and feedback) what teachers have appreciated the most, and how the leadership has been central in achieving its aims. 


\section{STEM Learning UK}

STEM Learning UK is a collaborative provision funded by a joint initiative through the Department for Education, the Department for Business, Energy and Industrial Strategy, the Wellcome Trust and the Gatsby Charitable Foundation [2]. Through this collaboration, STEM Learning provides teacher CPD in STEM subjects, brings STEM role models into schools (as part of the STEM Ambassador Programme) and provides bespoke, long-term support for groups of schools (in collaboration with private sector companies) through ENTHUSE Partnerships. This paper refers, though, to the Science Learning Partnerships (SLPs) that combine local expertise in teaching and learning in science, facilitating CPD and providing school-to-school support. They are led by schools and colleges with cutting-edge expertise in science themselves, who collaborate closely with local partners.

This case study is based on two neighbouring Science Learning Partnerships and examines the work that has been carried out by these STEM facilitators, through close collaboration with staff in the Early Years (nursery and reception classes covering ages three to five years) and Primary sectors, particularly in Key Stage One, which is the phase in England that covers Years 1 and 2 from ages five to seven. The SLPs facilitate science CPD across all key stages and into post-16 in Further Education settings, but for the purposes of this paper, our case study comes from EY and Primary specifically.

\subsection{The Impact of Schools Trusts}

COVID-19 had already hit the deployment of teachers to help support other staff. Inevitably, as much funding is now sent directly to Multi-Academy Trusts (MATs) also known as School Trusts (2), Local Authorities are beginning to decline much of their previous position, which has historically been very strong in the science arena. In this particular case study, the aim was to create a strong CPD offer across bordering SLP areas in order to create the best $\mathrm{CPD}$ offer for delegates across wide geographical regions; additionally, we aimed to use facilitator strengths to impact on the teaching and learning practice of delegates.

\subsection{The Impact of COVID-19}

The vast majority of the project that has formed this case study was completed prior to the onset of COVID-19 in England, i.e., from March 2020. However, the last sets of data collection (feedback of the evaluation of success from teaching staff) was successfully carried out online using a popular video technology platform - to follow up on anonymously submitted questionnaires, where staff had said that they were happy to be contacted and given their details for this to happen. The researchers involved in this project were particularly thankful for the recording function built into the online video technology deployed at that time, as it enabled the evaluation sessions with school staff to be recorded and, hence, a longer and more thorough coding process was able to be deployed [3].

Although the overall amount of CPD increased dramatically in the SLPs (in this case study) at the start of the first lockdown, and through the Summer of 2020, the face-to-face (F2F) workload by the autumn of 2021 was still nowhere near what it was pre-COVID-19, as schools were still not having visitors back in them to deliver school CPD. There is a range of different reasons for this, including: continuing waves of COVID-19 infection in schools, continuing disruption of staffing from infection, the impact of 'Catch Up funding' on time-of-school staff and the overall disruption and exhaustion felt in schools from the international epidemic [4]

\subsection{Early Years and Primary Leadership}

Moyles [5] has commented that staff in early years settings have had to adapt to many changes and demands, from local authorities and national government, and none more so than those who find themselves in leadership and management roles in increasingly complex early years settings. The facilitators involved in these Science Learning Partnerships are genuinely passionate about young children gaining the access to science that is set out 
in the Science programmes of study, i.e., key stages 1 and 2, in the National Curriculum in England [6]. That paper from 2013, lays out the:

- Purpose of study

- Aims

- Scientific knowledge and conceptual understanding

- The nature, processes and methods of science

- Spoken language

- School curriculum

- Attainment targets

With the revised Early Years Foundation Stage (EYFS) Paper [7] being published during the roll out of this particular project, many of the comments at SLP termly meetings were about the lack of exposure of children in EY and KS1 settings to these scientific curriculum areas, and staff had this as a definite priority target to tackle moving forward. The Association of Science Education published a text back in 2000, 'Science 3-6, laying the foundations in the Early Years' [8], which, although it may sound dated, is a quality assured text from the STEM Learning UK library for educators in the field and shows the usefulness of being part of an umbrella organisation that monitors the quality of useful and usable literature in the field on behalf of busy staff.

\subsection{The Aim of the Project}

Before the start of the 2018/2019 contract with STEM Learning, the Midlands SLP in question had not been in regular contact with the neighbouring SLP (in the North). This lack of contact changed in March 2018, when, with the support and encouragement of our Regional Development Lead (RDL) who knew both regions, we organised our first joint planning meeting. The aim of the project was to see if collaborative work could take place across the SLPs and to see if this could be useful for staff and young children in the areas concerned.

The nature of this joint collaborative work, was around identifying:

- precisely what was needed,

- if capacity existed to provide any joint sessions,

- whether or not it was worth sharing any facilitation (subject knowledge expertise) across areas,

- if delivery of sessions was one off or needed regularly,

- how any facilitated CPD could be better supported longer term,

- what leadership structures covered the Early Years and Primary settings concerned,

- what continual work could be done, moving forward,

- what sustained provision looked like, and,

- later, the nature of the work shifted to analysing what this looked like, post-COVID-19.

The joint meetings, at first hesitant, across a wide geographical area slowly became common practice, and, as of 2021, we now have regular meetings (half termly) both with the EY/Primary and Secondary elements of the SLPs and keep in regular email contact about opportunities for schools across the adjoining areas. These meetings, though, have covered a lot of ground, and staff have had to be sure that they are investing in longer term provisions that will support both areas.

\section{Methodology}

The initial meeting was aimed at setting up joint courses in the northern area of our SLP which borders the southern area of the neighbouring SLP. It made practical sense, rather than running small courses or having to cancel courses, for us to join together, to run joint courses in a more central venue for both SLPs. Following our meetings, the group shared their areas of priority for their target schools so that we could try to tailor continuing professional development to suit both SLP areas' schools, this gave a much more coherent 
approach and a greater possibility of increased numbers on courses. The project has been anonymised, and schools, staff, and SLPs have been given pseudonyms where necessary.

This joint collaborative working meant that the leaders involved could share knowledge around schools and whether or not they were part of the Local Authority 'clusters' of schools, in particular localities, or were part of Multi-Academy Trusts, and, if so, where their connections were to sustain the development associated with the continuing professional development that was being provided. These meetings led to a knowledge sharing in the leadership, so that a regional picture could be built up to see which MATs and/or Clusters were in need of more specific help with their Early Years and Primary KS1 input particularly. Some of the collaborative events that have happened so far include:

- Subject Leader courses,

- $\quad$ EYFS and KS1 subject knowledge,

- Assessment courses (in these Key Stages), and

- Working Scientifically courses.

The regular email contact and meetings have enabled us to progress from delivering morning/afternoon/twilight CPD and led on to several whole day events together including two conferences, which were delivered for the alternate SLP. For example, A delivering for the Northern SLP and B to the Midlands SLP, in order to better share and rotate our expertise to a wider range of school staff.

These wider events revealed gaps in local knowledge, that subsequently generated specific follow up work with individual schools, such as:

- $\quad$ 1:1 support for the Science Subject Leader

- Attendance on Working Scientifically course - then for the Subject Leader to cascade ideas and strategies and to begin to build this into school/class planning

- Bespoke support for Science and Subject Leader followed by a twilight session on Working Scientifically for the whole staff led by the SLP Primary Lead

- New planning grids were created with the support of STEM resources to aid with assessment and built into the planning of both long- and short-term plans using ideas and strategies from these two main assessment resources

Discussions were then held on the topic of using differentiation strategies for science across the year groups and use of resources to broaden horizons and apply understanding, for example, the use of Practical Action, Awareness of Health and Safety and the role of the Consortium of Local Education Authorities for the Provision of Science Services (CLEAPSS) for all staff when carrying out new investigations/reassess current investigations [9]. The focus of the 'Working Scientifically' course was subsequently cascaded to the staff through the Science Subject Leader (SSL) and continued as a focus along with implementation of increasingly focussed planning documents using the wider Working Scientifically resource bank, as a key element for planning progression of the skills and the enquiry methods

\section{Findings}

What Have Been the Recorded Impacts of These Events?

On an individual level, the Science Subject Leader (SSL) began to understand and feel confident in the role as a science subject leader and was able to describe what high-quality science teaching looked like in order to demonstrate this in the classroom and then plan opportunities for team teaching and other staff CPD/support. It was noted that:

- The SSL gained a clearer vision of attainment and progress across the school.

- This led the SSL, with SLP support, to create an action plan which exemplified a clear direction for science within the school including considering how new initiatives in science might be implemented across the school in order to improve the quality of thinking and learning in schools.

- $\quad$ Teachers began to demonstrate an increased knowledge of progression in scientific enquiry. 
- All staff began to implement a wider range of strategies for planning, resourcing and organising enquiry in their classrooms.

- There was an increased progression in scientific enquiry through the school.

- Staff all created their own resources on asking questions for the next school terms and began to link them into their planning.

- Staff began to introduce a wider range of strategies for pupils to use when questioning and then organising their enquiry.

The feedback also noted that there was an increase in the different types of enquiry children were engaged in so that they could explore the world around them more widely, and more children's ideas were developed into the science lessons throughout the school. The staff all signed into and began using other STEM resources such as Explorify, Terrific Scientific and Reach out Reporter [10] to increase the breadth of science understanding and application.

The developing relationships between the SLPs has had a positive impact on a wide range of local teachers at both the EY/Primary and Secondary levels and is, therefore, assumed to be having a knock-on impact on the young people whose staff we are training (see quotes below). This impact is largely around the opportunities to network across not only the regional boundaries discussed above, but also the Local Authority (LA) and Multi Academy Trust (MAT) boundaries to discuss ideas and initiatives rather than the often 'insular' approach that many MATs have been noticed to be adopting. For example, younger staff in schools were often unaware of the role of the Consortium of Local Education Authorities for the Provision of Science Services [9] and other associated relevant organisations such as the Association of Science Education [11], so by working towards joint events, particularly with the delivery of staff training days inside newly developed School Trusts, the facilitators involved were able to rapidly improve the subject knowledge base of staff across a wide geographical area.

The analysis of the Impact Tool Kit (ITK) data from the platform evidenced that the EYFS/KS1 courses, for example, were very well received by all participating delegates. They all 'agreed strongly' that it would have impact on their future practice and on the students that they teach. The comments below show how valuable they found the day:

'This was a practical, exciting and informative day where there was an excellent mix of activities.'

'Great ideas for practical activities that are open ended.'

'All sessions were good and will enable me to implement practically in school with lots of ideas which I can adjust to our curriculum for the better. Great interactive sessions really enjoyed sharing and taking away ideas.'

'Ideas for practical activities were good, because I usually find it difficult to come up with ideas and now I have a lot more. Very interesting and informative course.'

'All sessions were great. I will take back lots of ideas to my school and classroom. Love how interactive and involved we were.'

When the delivery team met to evaluate the increased CPD provision and looked at the coding that the researcher had provided, it was clear that an impact had been demonstrated on the teachers in the SLPs. It was realised that working closely across the SLPs had made life much easier for all involved. No negative feedback comments were returned in the data collection. There was a number of reasons for that, including:

- $\quad$ sharing resources

- creating resources together

- discussing and resolving issues

- developing increased capacity.

This last point is a particularly significant point, as, although a wider geographical area had been covered, increased capacity had enabled this to happen more effectively. This has meant that we have decided to continue to work together in the future, meeting 
at least every couple of months-booking a regular half-termly meeting into the school calendar. This has enabled us to fully understand what each of us is doing, and where it is best to concentrate efforts given the complex nature of the political and physical backdrop with MATs and COVID-19.

This working relationship across SLPs has developed significantly and is having a really positive impact on the outcomes and financial aspects for neighbouring SLPs but, more critically, also having a knock-on effect to teachers, schools and the young people. A contributory factor might also be that all the colleagues involved in this project have been employed by these two SLPs since at least 2018, have established relationships with staff in schools and have not had personnel changes whilst the project has been running-as we have experienced in other projects—-which have been disruptive to their success.

\section{Conclusions}

This project set out to increase the scientific working knowledge of those who are teaching in the Early Years Foundation Stage and Key Stage One in an area in the Midlands and a neighbouring area in the North. It was not known whether collaboration of this type was wanted, either by the 'competing' facilitators or by the different geographical groups of school staff. There are many current issues within schools that have impacted leadership and the roll out of this collaborative partnership in Early Years and Primary KS1 that have been raised above, not least the significance of the political, physical and economic landscapes.

The increased number of MATs (or school trusts) [2] in England, leading to the decline of funding - and the loss of some of the wider functions - of the Local Authorities, may then also have a potential impact on the way that some science education in England has been established. The changing nature of the physical structures of schools relating to the issues with COVID-19, with fewer visitors, and less time to hold face-to-face continuing professional development, and the additional costs of all of this to schools comes at a time of real-term budget cuts in education in England [12]. It, therefore, seems to us, that the most advantageous way to continue to support the Early Years and Primary Key Stage One schools, in particular, is through this extended network of regional collaborative provisions that can work more collaboratively and across artificial boundaries, providing that the staffing and motivation exists to achieve this.

Author Contributions: Conceptualization, D.E.O. and J.B.; methodology, J.B.; software, A.C.; validation, D.E.O., J.B. and A.C.; formal analysis, D.E.O.; investigation, J.B.; resources, A.C.; data curation, J.B.; writing—original draft preparation, D.E.O.; writing—review and editing, D.E.O.; visualization, A.C.; supervision, J.B.; project administration, J.B.; funding acquisition, A.C. All authors have read and agreed to the published version of the manuscript.

Funding: This research received no external funding.

Institutional Review Board Statement: Not applicable.

Informed Consent Statement: Informed consent was obtained from all subjects involved in the study.

Data Availability Statement: Not applicable.

Conflicts of Interest: The authors declare no conflict of interest.

\section{References}

1. STEM. 2021. Available online: https://www.stem.org.uk/about-us/our-supporters (accessed on 18 September 2021).

2. Cruddas, L. 'Systems of Meaning: Three Nested Leadership Narratives for School Trusts', Confederation of School Trusts. 2020. Available online: https://cstuk.org.uk/assets /CST-Publications/10027_CST_Three_Nested_Leadership\%20_White_Paper\%20 (002).pdf (accessed on 28 October 2021).

3. Saldana, J. The Coding Manual for Qualitative Researchers, 2nd ed; Sage: London, UK, 2021.

4. Thompson, P. School Leaders Work and Well-being Project, University of Nottingham. 2021. Available online: https:// schoolleadersworkandwellbeing.com/2021/10/25/how-does-it-feel-to-lead-a-school-during-the-pandemic/ (accessed on 25 October 2021). 
5. Moyles, J. Effective Leadership and Management in the Early Years; Open University Publishers: Maidenhead, UK, 2006.

6. Department for Education. Primary National Curriculum. 2013. Available online: https://assets.publishing.service.gov.uk/ government/uploads/system/uploads/attachment_data/file/425618/PRIMARY_national_curriculum_-_Science.pdf (accessed on 18 September 2021).

7. Early Years Foundation Framework, DfE 2021, Statutory Framework for the Early Years Foundation Stage (EYFS). 2021. Available online: https:/ / www.gov.uk/government/publications/early-years-foundation-stage-framework--2 (accessed on 18 September 2021).

8. Association of Science Education Published a Text Back in 2000, 'Science 3-6, Laying the Foundations in the Early Years'. Available online: https:/ / www.stem.org.uk/system/files/elibrary-resources/legacy_files_migrated/18126-LAYING\%20THE\% 20FOUNDATIONS\%20IN\%20THE\%20EARLY\%20YEARS.pdf (accessed on 18 September 2021).

9. CLEAPSS. 2021. Available online: http://science.cleapss.org.uk/Policies/What-Is-Cleapss.aspx (accessed on 18 September 2021).

10. Primary Resources for Home Learning. 2020. Available online: https://www.stem.org.uk/home-learning/primary (accessed on 18 September 2021).

11. Association of Science Education (ASE). 2021. Available online: Home \T1 \textbar\{\}www.ase.org.uk (accessed on 18 September 2021).

12. Sibieta, L. Larger Funding Cuts for Schools in Poor Areas Leave Them Badly Placed to Deal with COVID-19 Challenges, Institute for Fiscal Studies (IfFS). 2020. Available online: https:/ /ifs.org.uk/publications/15026 (accessed on 18 September 2021). 